\title{
Pemberdayaan Masyarakat Miskin Melalui Peningkatan Layanan Kesehatan Oleh Rumah Sehat BAZNAS Yogyakarta di Desa Wukirsari
}

\author{
Hendrik Basguni Sukendar \\ UIN Sunan Kalijaga
}

Naskah diterima 10 Mei 2018, direvisi 19 Juni 2018, disetujui 12 Juli 2018

\begin{abstract}
In order to realize the social welfare as set forth in law No. 11 year 2009, where social welfare is to satisfy the needs of citizen's material conditions, spiritual, social in order to be worth living and able to develop themselves, so that it can carry out its social function. Healthy Home BAZNAS Yogyakarta as one of the institutions engaged in the field of humanity trying to embody these conditions through improved health care services. This study sought to examine how the empowerment of the poor is done by RSB Wukirsari Village in Yogyakarta. The research method used is descriptive-qualitative. The data collection techniques used is observation, interview and documentation. In determining the informants researchers using the technique of purposive and snowball. Then the validity of the data used the technique of triangulation. The results of this research suggests that there is community empowerment strategies undertaken RSB Yogyakarta in the field of health, among others; health advocacy, partnership to obtain social support and the implementation of community empowerment in the field of health
\end{abstract}

Keywords: Empowerment, Health, RSB Yogyakarta, The Wukirsari village

Abstrak Dalam rangka mewujudkan kesejahteraan sosial sebagaimana yang termaktub dalam UU RI No. 11 tahun 2009, dimana kesejahteraan sosial adalah kondisi terpenuhinya kebutuhan material, spiritual, dan sosial warga negara agar dapat hidup layak dan mampu mengembangkan diri, sehingga dapat melaksanakan fungsi sosialnya. Rumah Sehat BAZNAS Yogyakarta sebagai salah satu lembaga yang bergerak di bidang kemanusiaan mencoba mengejawantahkan kondisi tersebut melalui peningkatan layanan kesehatan. Penelitian ini berusaha mengkaji bagaimana pemberdayaan masyarakat miskin yang dilakukan oleh RSB Yogyakarta di Desa Wukirsari. Metode 
penelitian yang digunakan adalah deskriptif-kualitatif. Teknik pengumpulan data menggunakan observasi, wawancara dan dokumentasi. Dalam menentukan informan peneliti menggunakan teknik purposive dan snowball. Kemudian validitas data menggunakan teknik triangulasi. Hasil penelitian ini mengemukakan bahwa terdapat strategi pemberdayaan masyarakat yang dilakukan RSB Yogyakarta di bidang kesehatan, antara lain; advokasi kesehatan, menjalin kemitraan (partnership) untuk memperoleh dukungan sosial (social support) dan implementasi pemberdayaan masyarakat di bidang kesehatan.

Kata Kunci: Pemberdayaan, Kesehatan, RSB Yogyakarta, Desa Wukirsari

\section{A. PENDAHULUAN}

Sebuah bangsa yang maju tentunya mendambakan agar rakyatnya dapat hidup sejahtera. Kehidupan yang adil, makmur serta terpenuhi semua kebutuhan rakyatnya. Dalam Undang-undang Republik Indonesia No. 11 tahun 2009 tentang Kesejahteraan Sosial, menerangkan bahwa kesejahteraan sosial adalah kondisi terpenuhinya kebutuhan material, spiritual, dan sosial warga negara agar dapat hidup layak dan mampu mengembangkan diri, sehingga dapat melaksanakan fungsi sosialnya (UU kesos No. 11 Tahun 2009).

Kesejahteraan masyarakat saat ini menurut UNDP diukur oleh Indeks Pembangunan Manusia (IPM) atau Human Development Index (Sulaeman, 2012:2). Salah satu indikator kesejahteraan adalah dibidang kesehatan. Kesehatan menjadi urgent karena merupakan kebutuhan dasar bagi setiap orang. Kesehatan merupakan hak asasi manusia yang harus terpenuhi dan salah satu unsur dalam mewujudkan masyarakat sejahtera. Kesehatan seringkali menjadi dampak dari berbagai permasalahan yang dialami individu dan lingkungan sekitarnya. Karena kesehatan merupakan modal awal bagi perkembangan potensi individu dalam hidup. 
Negara telah mengamanatkan dalam UU No. 36 Tahun 2009 tentang kesehatan, bahwa setiap orang mempunyai hak yang sama dalam memperoleh akses atas sumber daya dibidang kesehatan dan setiap orang mempunyai hak dalam memperoleh pelayanan kesehatan yang aman, bermutu, dan terjangkau. Aksesibiltas dan pelayanan kesehatan yang berkualitas harus didapatkan oleh seluruh rakyat Indoneisa tanpa membedakan status dan tidak diskriminatif, tanpa terkecuali untuk kelompok masyarakat miskin.

Untuk merealisasikan hal tersebut, pemerintah berupaya dengan mencanangkan Program Indonesia Sehat, diantaranya melalui Kartu Indonesia Sehat (KIS) yang diluncurkan tanggal 3 November 2014. Program ini; 1) menjamin dan memastikan masyarakat kurang mampu atau miskin untuk mendapat manfaat pelayanan kesehatan seperti dilaksanakan melalui Jaminan Kesehatan Nasional (JKN) yang diselenggarakan oleh BPJS Kesehatan; 2) perluasan cakupan PBI termasuk Penyandang Masalah Kesejahteraan Sosial (PMKS) dan Bayi Baru Lahir dari peserta Penerima PBI; serta 3) Memberikan tambahan manfaat berupa layanan preventif, promotif, dan deteksi dini dilaksanakan lebih intensif dan terintegrasi. Tujuan dari program tersebut adalah agar masyarakat dapat memenuhi kualitas hidupnya menjadi lebih baik yang tidak bergantung kepada siapapun, mampu mengembangkan potensi dirinya dengan menambah wawasan keilmuan, keterampilan serta dapat memanfaatkan sumber daya alam yang ada disekitar dan masyarakat dapat melaksanakan fungsi sosial sebagaimana mestinya.

Sesuai dengan Program Prioritas Nasional yaitu Percepatan Pengurangan Kemiskinan yang dijabarkan lebih lanjut dalam Kegiatan Prioritas untuk bidang kesehatan meliputi: Peningkatan Akses dan Mutu Pelayanan Kesehatan, Peningkatan Kesehatan Ibu, Anak dan KB, Pencegahan dan Pengendalian Penyakit, Percepatan Penurunan Stunting dan Penguatan "Germas" (Profil Kesehatan Provinsi D.I Yogyakarta, 2017). 
Dalam upaya mewujudkan kegiatan prioritas kesehatan di DIY bahkan ditingkat nasional, tidak dapat dilakukan sendiri oleh aparat pemerintah di sektor kesehatan, tetapi harus dilakukan secara bersama-sama dengan melibatkan peran serta multistakeholder. Segala upaya kesehatan selama ini dilakukan tidak hanya oleh sektor kesehatan saja, tetapi juga tidak luput peran dari sektor non kesehatan dalam upaya penyelenggaraan pelayanan kesehatan dan upaya mengatasi permasalahan kesehatan, karena masalah kesehatan tidak hanya dapat diintervensi oleh sektor kesehatan saja.

Sebagai upaya untuk mengatasi berbagai keterbelakangan masyarakat miskin, perlu dilakukan upaya pemberdayaan masyarakat yang masuk dalam semua bidang, diantaranya ialah di bidang kesehatan. Badan Amil Zakat Nasional (BAZNAS) merupakan badan resmi dan satu satunya yang dibentuk oleh pemerintah berdasarkan Keputusan Presiden RI No. 8 Tahun 2001 yang memiliki tugas untuk menghimpun dan menyalurkan zakat, infaq dan sedekah pada tingkat nasional. Diantara program dari BAZNAS adalah Rumah Sehat BAZNAS yang fokus programnya ialah peningkatan layanan kesehatan gratis bagi masyarakat miskin (Arsip Baznas D.I Yogyakarta, 2016).

Keberadaan Rumah Sehat Baznas di berbagai wilayah di Indonesia saat ini memang belum banyak, baru ada beberapa provinsi saja, termasuk diantaranya ialah di D.I.Yogyakarta tepatnya di Dusun Bibis Desa Timbul Harjo Kecamatan Sewon Kabupaten Bantul.

Sejalan dengan pembahasan di atas ada beberapa alasan yang membuat peneliti tertarik untuk melakukan penelitian di Rumah Sehat Baznas Yogyakarta dalam upayanya melakukan pemberdayaan masyarakat miskin melalui peningkatan layanankesehatandi Desa Wukirsari:

Pertama rumah Sehat Baznas Yogyakarta hadir dalam menjawab persoalan kemiskinan, yang fokus upayanya adalah melakukan pemberdayaan masyarakat dibidang kesehatan. Kedua program layanan kesehatan cuma-cuma bagi masyarakat miskin 
yang dilakukan secara gratis tanpa dipungut biaya sedikitpun yang dikhususkan untuk masyarakat yang termasuk dalam kategori mustahiq (orang terlantar, fakir miskin, anak yatim dan orang cacat).

\section{B. METODE PENELITIAN}

Penelitian kualitatif mengenai pemberdayaan masyarakat miskin melalui peningkatan layanan kesehatan oleh Rumah Sehat Baznas Yogyakarta di Desa Wukirsari. Informan dalam penelitian ini adalah stakeholeders Rumah Sehat Baznas (RSB) Yogyakarta, ketua kader sehat dan masyarakat Desa Wukirsari. Teknik pengumpulan data melalui observasi ke lokasi penelitian, kemudian wawancara dengan masyarakat Desa Wukirsari sebagai dampingan Rumah Sehat Baznas Yogyakarta dan dilengkapi dengan dokumen atau arsip pendukung sebagai penguat hasil observasi dan wawancara. Validitas data menggunakan Teknik triangulasi sumber dan triangulasi metode untuk membandingkan dan mengecek balik derajat kepercayaan suatu informasi yang diperoleh melalui waktu dan alat yang berbeda dalam metode kualitatif. Analisis data dalam penelitian ini menggunakan teknik analisis data yang dikembangkan oleh Miles Huberman yaitu pertama pengumpulan data hasil wawancara, observasi, dan berbagai arsip atau dokumentasi. Kemudian menajamkan, menggolongkan, mengarahkan, mereduksikan kemudian menyajikan data dan penarikan kesimpulan (Miles, Huberman and Saldana 2013; Creswell, 2017).

\section{HASIL DAN PEMBAHASAN}

Proses pemberdayaan masyarakat tentunya memiliki strategi dalam upaya pencapaiannya. Seperti halnya yang dilakukan oleh Rumah Sehat Baznas Yogyakarta dalam melakukan pemberdayaan masyarakat di bidang kesehatan. Sasaran primer yang menjadi fokusnya adalah masyarakat Desa Wukirsari yang mengalami masalah kesehatan serta masyarakat yang memiliki pemahaman kesehatan yang rendah. Adapun tujuan dari program ini adalah 
untuk membantu masyarakat Desa Wukirsari dalam meningkatkan pengetahuan dibidang kesehatan serta dapat memaksimalkan pelayanan kesehatan bagi masyarakat miskin atau kurang mampu. Strategi yang dilakukan Rumah Sehat BAZNAS dalam peningkatan layanan kesehatan antara lain:

\section{Advokasi Kesehatan}

Berdasarkan hasil Rapat Kerja Nasional tahun 2015, bahwa Rumah Sehat Baznas Pusat memerintahkan kepada Rumah Sehat Baznas yang berada disetiap daerah untuk memiliki program ciri khasnya masing-masing sesuai dengan kebutuhan masyarakat ditingkat lokal. Hal ini yang membedakan Rumah Sehat Baznas dengan Puskesmas. Jika Puskesmas programnya mengikuti perintah dari pusat, namun berbeda dengan RSB yang diperkenankan untuk menyesuaikan programnya dengan masyarkat sekitar. Hal ini ditegaskan oleh Mas Rio selaku Kabag PSDM Rumah Sehat Baznas, sebagai berikut:

"Jadi bukan dari pusat harus buka ini, buka ini, tapi lebih kedesentralisasi, karena memang menyesuaikan daerah. Rapat rakernas tahun 2015 kmren malah meminta setiap daerah itu punya ciri khas sendiri sendiri, jadi punya program ciri khas sesuai dengan masyarakatnya, ya itu mungkin yang berbeda denga layanan kesehatan secara umum, kayak dipuskesmas itu kan sudah ada „,' dia harus begini begini dari pusat, tapi kalo dari baznas, silahkan menyesuaikan dengan masyarakat sekitarnya, nahh itu yang menjadi unggulan".

Sebagaimana dipaparkan di atas bahwa program kerja Rumah Sehat Baznas memang sangat fleksibel karena lebih kedesentralisasi, artinya ketika memang ada kebutuhan yang mendesak hal itu bisa langsung direalisasikan tanpa harus menunggu keputusan dari pusat. Jadi sejauh ini Rumah Sehat Baznas masih bisa menentukan arahnya sendiri perdaerah, tidak 
harus sesuai dengan perintah pusat, karena memang menyesuaikan daerahnya masing-masing.

\section{Menjalin Kemitraan untuk Memperoleh Social Support}

Rumah Sehat Baznas Yogyakarta sejak awal berdiri hingga saat ini selalu menjalin kerjasama dengan lembaga-lembaga lain sebagai upaya dalam memaksimalkan program. RSB Yogyakarta selalu bekerjasama dengan pihak lain dalam mewujudakan masyarakat miskin yang sehat dengan pelayanan yang berkualitas. Hal tersebut dapat dibuktikan dengan melihat beberapa logo lembaga yang telah bekerjasama dengan RSB Yogyakarta dan terpasang didalam gedungnya. Lembaga yang sudah bekerjasama anatara lain; Universitas Islam Indonesia, Universitas Gadjah Mada, Metro TV, Badan Amil Zakat Daerah (Bazda) dan lain-lain.

Selain itu, Rumah Sehat Baznas Yogyakarta juga bekerjasama dengan Pemerintah Desa Wukirsari sebagai wilayah dampingan untuk ikut serta membantu dalam pendataan. Pemerintah Desa melalui kepala Dusun dilibatkan dalam mendata warga yang dianggap tidak mampu atau faqir miskin serta yang dianggap berhak menerima zakat. Lebih lanjut Mas Rio selaku Kabag PSDM Rumah Sehat Baznas mengatakan bahwa:

"Kita melibatkan pihak lain,, kita melibatkan perangkat desa, jadi sudah masuk kebirokrasi, jadi perangkat desa mendata warganya melalui kepala desa kemudian turun kekepala dusun, itu mendata apa yang mereka anggap tidak mampu, faqir miskin yang masuk golongan penerima zakat, kemudian mereka mengajukan ke RSB Yogyakarta untuk ditindak lanjuti dengan survey, sekarang kita pakai metode birokrasi jadi masuk kedesa, terus selain itu kita juga dalam menjalankan program ini tidak pernah sendiri.....”.

Strategi yang kedua ini sejalan dengan yang dikemukakan oleh Departemen Kesehatan, yaitu Kemitraan (Partnership) untuk Memperoleh dukungan Sosial (Social Support). Dimana RSB menyamakan persepsi dan meningkatkan pemahaman tentang 
kemitraan untuk mewujudkan Indonesia Sehat. Kemudian RSB menjalin jaringan kemitraan dibidang pembangunan kesehatan serta menggalang sumber daya baik tenaga, dana dan sarana.

\section{Implementasi Pemberdayaan Masyarakat di Bidang Kesehatan}

Membentuk Kader Sehat-Kader adalah tenaga yang berasal dari masyarakat, dipilih oleh masyarakat itu sendiri, dan bekerja secara suka rela untuk menjadi penggerak masyarakat di wilayahnya. Kader Rumah Sehat BAZNAS Yogyakarta merupakan perwakilan masyarakat yang berperan dalam membantu pelaksanaan program HT dan DM Center untuk memberikan pelayanan kesehatan kepada masyarakat (Arsip RSB Yogyakarta, 2016).

RSB Yogyakarta memakai strategi ini untuk wilayah yang jauh dari lokasi Rumah Sehat. Kader Sehat ini dilatih untuk bisa membantu RSB dalam melakukan pendampingan masyarakat dalam bidang kesehatan. Tujuan dibentuknya kader adalah agar terselenggaranya upaya pencegahan penyakit oleh kader terhadap masalah-masalah kesehatan yang ada di masyarakat, memudahkan koordinasi antara Rumah Sehat Baznas DIY dengan masyarakat untuk melaksanakan upaya-upaya kesehatan di Desa Wukirsari serta meningkatkan pengetahuan masyarakat di lingkungan kader dalam hal kesehatan, khususnya mengenai penyakit Hipertensi dan Diabetes.

Menjadi Kader Sehat harus melewati beberapa tahapan; open recrutiment, penyeleksian, setelah lolos seleksi akan diberi pelatihan selama satu tahun oleh RSB Yogyakarta, pembagian tugas dan pelaksanaan. Kader sehat di Desa Wukirsari dibentuk pada tahun 2012, waktu itu sebanyak dua puluh lima kader. Kemudian mereka diberi pelatihan selama satu tahun, seperti: mengajarkan tensi, kontroling obat, diajarkan bagaimana cara meminum obat untuk para pasien dan sebagainya terkait dengan program yang diadakan oleh RSB Yogyakarta. 
Layanan Kesehatan-Rumah Sehat Baznas Yogyakarta memiliki program-program unggulan layanan kesehatan antara lain; 1) Layanan Dalam Gedung (LDG) dan Layanan Luar Gedung (LLG). Layanan Dalam Gedung diperuntukkan bagi pasien yang dapat menjangkau lokasi RSB Yogyakarta, sedangkan Layanan Luar Gedung sebaliknya, yaitu mendatangi wilayah dampingan yang jauh dari lokasi RSB Yogyakarta. 2) RSB Yogyakarta memberikan layanan pengobatan gratis kepada pasien dengan standar pelayanan prima, 3) RSB Yogyakarta menerapkan sistem tanpa kasir sehingga pasien dapat langsung berobat, 4) RSB Yogyakarta juga menerima pasien dalam kondisi darurat tanpa melihat status kaya atau miskin.

Pelatihan-Dalam upaya meningkatkan sumber daya manusia, RSB Yogyakarta mengadakan refresh keilmuan sebagai upaya meningkatkan kapasitas pengetahuan serta keterampilan melalui berbagai training dan pelatihan untuk stakeholders, karyawan serta kader sehat Desa Wukirsari. RSB Yogyakarta juga menerima undangan menjadi narasumber untuk mengisi kegiatan yang berkaitan dengan kesehatan.

Penyuluhan-Program penyuluhan dilakukan Rumah Sehat BAZNAS Yogyakarta dengan tujuan untuk mensosialisasikan kepada masyarakat akan pentingnya menjaga kesehatan, memberikan informasi tentang berbagai macam penyakit dan cara pengobatannya. Masyarakat juga dihimbau agar menyampaikan informasi tersebut kepada masyarakat lain dilingkungannya, agar dapat memanfaatkan layanan kesehatan secara gratis dan berkualitas. Kegiatan ini dilakukan bersamaan dengan program layanan kesehatan luar Gedung/ LLG setiap tiga puluh lima hari sekali mengikuti penanggalan jawa.

\section{KESIMPULAN}

Hasil penelitian pemberdayaan masyarakat miskin melalui peningkatan layanan kesehatan oleh Rumah Sehat Baznas Yogyakarta di Desa Wukirsari dapat ditarik kesimpulan bahwa: 
Advokasi kesehatan yang dilakukan Rumah Sehat Baznas Yogyakarta kepada pengurus pusat memang sangat fleksibel, karena lebih kedesentralisasi. Artinya ketika memang ada kebutuhan yang mendesak hal itu bisa langsung direalisasikan tanpa harus menunggu keputusan dari pengurus pusat. Jadi sejauh ini Rumah Sehat Baznas Yogyakarta masih bisa menentukan arahnya sendiri perdaerah, tidak harus sesuai dengan perintah pusat, karena memang menyesuaikan daerahnya masing-masing.

Menjalin kemitraan untuk memperoleh social support sudah dilakukanRumah Sehat Baznas Yogyakarta sejak awal berdiri. RSB Yogyakarta sudah menjalin kerjasama dengan lembaga-lembaga lain sebagai upaya dalam memaksimalkan programnya. Tujuannya adalah untuk mewujudkan masyarakat miskin yang sehat dan kuat dengan pelayanan yang berkualitas.

Implementasi pemberdayaan masyarakat dibidang kesehatan oleh RSB Yogyakarta meliputi; 1) Membentuk kader sehat. Kader Rumah Sehat BAZNAS Yogyakarta merupakan perwakilan masyarakat yang berperan dalam membantu pelaksanaan program HT dan DM Center untuk memberikan pelayanan kesehatan kepada masyarakat. Tujuan dibentuknya kader adalah agar terselenggaranya upaya pencegahan penyakit, memudahkan koordinasi serta meningkatkan pengetahuan masyarakat di lingkungan kader dalam hal kesehatan. Layanan kesehatan. RSB Yogyakarta memiliki program-program unggulan layanan kesehatan antara lain: layanan dalam gedung dan layanan luar Gedung, layanan prima, sistem berobat tanpa kasir, menerima pasien dalam kondisi gawat darurat. Pelatihan-pelatihan. Strategi ini untuk meningkatkan kapasitas pengetahuan serta keterampilan stakeholder, karyawan serta kader sehat. Penyuluhan, kegiatan ini bertujuan untuk mensosialisasikan kepada masyarakat akan pentingnya menjaga kesehatan, memberikan informasi tentang berbagai macam penyakit dan cara pengobatannya. Masyarakat juga dihimbau agar menyampaikan informasi tersebut kepada masyarakat lain dilingkungannya 


\section{DAFTAR PUSTAKA}

Bagong, S, 2013, Anatomi Kemiskinan dan Strategi

Penanggulangannya, Malang: In- Trans Publishing.

Basrowi dan Suwandi, 2008, Memahami Penelitian Kualtitatif, Jakarta:

PT Rineka Cipta.

Edi, S,2009, Membangun Masyarakat Memberdayakan Rakyat,

Bandung: PTRefika Aditama.

Endang, Sutisna, S, 2012, Pemberdayaan Masyarakat di Bidang

Kesehatan, Yogyakarta: Gadjah Mada University Press.

Imam, S \& Tobroni, 2001, Metodologi Penelitian Sosial-Agama,

Bandung: PT Remaja Rosdakarya.

Koentjaraningrat, 2009, Pengantar Ilmu Antropologi, Jakarta : PT

Rineka Cipta.

Lexy J, M, 2010, Metodologi Penelitian Kualitatif, Bandung: PT Remaja

Rosdakarya.

Majelis Ulama Indonesia, 1992, Air, Kebersihan dan Kesehatan

lingkungan Menurut Ajaran Islam, Jakarta: Majelis Ulama Indonesia.

Mukono,H.J., 2006, Prinsip Dasar Kesehatan Lingkungan Edisi kedua, Surabaya:Airlangga University Press.

Profil Kesehatan Provinsi D.I Yogyakarta tahun 2017.

Republik Indonesia, 2009, Undang-Undang RI Nomor 36 Tahun 2009 tentang Kesehatan, Jakarta: Kementrian Kesehatan.

Republik Indonesia, 2009, Undang-Undang RI Nomor 11 Tahun 2009 tentang Kesejahteraan Sosial, Jakarta: Kementrian Sosial.

Rr. Siti Kurnia, W, dkk., 2015, Pemberdayaan Masyarakat Marginal, Yogyakarta: Pustaka Pelajar.

www.kbbi.web.id, diakses pada tanggal 1Agustus 2016 pukul 09.00 WIB.

http:// pusat.baznas.go.id/rsb-yogyakarta, diakses pada tanggal 4 Juni 2016 pukul 19.20 WIB.

www.depkes.go.id, diakses pada tanggal 15 Oktober 2018 pukul 20.30 WIB. 